\title{
Fall Risk Assessment of Rural Elderly Population in Korea
}

\author{
Dahye Park, MD, Hongsik Jo, MD, Chul Ho Yoon, MD, Eun Shin Lee, MD, \\ Min-Kyun Oh, MD, Chang Han Lee, MD
}

Department of Rehabilitation Medicine, Gyeongsang National University Hospital, Gyeongsang National University School of Medicine, Jinju, Korea

Objective To investigate the risk factors for fall in the elderly population residing in rural areas of Korea and provide useful data for their prevention.

Methods As part of farmers' health promotion project, a retrospective study was conducted with a total of 350 elderly people recruited from March 2016 to December 2016. These subjects were divided into two groups: 254 non-fallers and 96 fallers. A person who fell to the floor at least once in the past year was defined as a faller. Participants were asked to visit the hospital once. The demographic characteristics, social environment, and educational levels were surveyed using a questionnaire. Physical examination was performed in the following order: cognitive function, lower leg strength and torque, body composition, and knee image test.

Results Statistically significant factors for falls in univariate analysis were female gender, age, living alone, educational level less than middle school, skeletal muscle mass, Mini-Mental State Exam, knee osteoarthritis, hip torque, hip power mean, knee torque, and knee power mean. Multivariate analysis was performed to identify variables most relevant to falls among statistically significant factors in univariate logistic analysis. It was confirmed that female gender and age of 70-79 years were statistically significant factors related to falls.

Conclusion Female gender and elderly status (70-79 years) are important risk factors for falls in rural areas underscoring the need for special attention when considering risk factors for falls among the elderly living in rural areas.

Keywords Falls, Aged, Rural area, Risk factors, Korea

\section{INTRODUCTION}

South Korea is home to a rapidly aging population.
Health problems of the elderly are emerging as major social issues including aging and degenerative diseases [1]. Health and social problems represent major issues

Received August 28, 2018; Accepted November 16, 2018

Corresponding author: Chang Han Lee

Department of Rehabilitation Medicine, Gyeongsang National University Hospital, 79 Gangnam-ro, Jinju 52727, Korea. Tel: +82-55-750-9639, Fax: +8255-750-8255, E-mail: ychkhk1407@gmail.com

ORCID: Dahye Park (http://orcid.org/0000-0002-5396-8221); Hongsik Jo (http://orcid.org/0000-0002-4778-4397); Chul Ho Yoon (http://orcid.org/ http://orcid.org/0000-0003-4916-4180); Eun Shin Lee (http://orcid.org/0000-0002-7764-1522); Min-Kyun Oh (http://orcid.org/0000-0003-0258-6298); Chang Han Lee (http://orcid.org/0000-0001-8351-5226).

(c) This is an open-access article distributed under the terms of the Creative Commons Attribution Non-Commercial License (http://creativecommons.org/ licenses/by-nc/4.0) which permits unrestricted noncommercial use, distribution, and reproduction in any medium, provided the original work is properly cited. Copyright ( 2019 by Korean Academy of Rehabilitation Medicine 
because the numbers of the elderly are expected to rise, which increases the risk of falls and other consequences $[1,2]$. In particular, complications caused by falls in the elderly are undermining the quality of life and increasing medical costs [2].

Falls are major causes of mortality, disability, and physical limitation in the elderly. In 2011, 21\% of Koreans above the age of 65 years experienced a fall while $47.4 \%$ experienced after-effects of a fall [2]. Falls can cause physical and mental damage limiting body movement because of pain, thus limiting their social activities [3]. Elderly population in the community often suffer physical losses such as muscular dystrophy, altered equilibrium, and endurance due to lack of exercise. As a result, their daily life functions are impaired [4].

Studies related to falls have focused on the number of patients, risk factors, and outcomes $[1,3,5]$. These studies vary by country and regions and employ a variety of assessment tools, items, and scoring systems. Several studies have shown that the fall rate in South Korea varies widely from region to region. The risk factors for falls have been extensively documented making it difficult to identify factors necessary for education of the elderly population about fall prevention $[4,5]$.

About $25 \%$ of all elderly over the age of 65 years reside in the rural areas of South Korea, and exhibit a range of disabilities in urban areas due to continuous subsistence activities [6]. Elderly people in rural areas adopt a traditional life style compared to cities. Most of them are engaged in outdoor activities. Rural areas have many uneven or sloping road surfaces. Thus, the elderly population in the rural areas are at a higher risk of falls compared to those in the urban areas. In addition, a majority of the elderly individuals living in rural areas are alone with limited daily activities, a lower educational level, and an increased risk of developing musculoskeletal diseases due to aging and agricultural life style $[5,7,8]$.

A limited number of studies investigated the conditions and risk factors of falls in the rural elderly population. Most of the previous studies were conducted with community or hospitalized patients based on interviews or questionnaires $[3,9,10]$. Cho et al. [3] have reported that an elderly person who lives alone or independently with heart disease or urinary incontinence has an increased risk of falling. Sohng and Choi [9] have reported that ankle joint strength, education, marital status, visual func- tion, and daily life performance scores are significant risk factors for elderly falls. Ryeom et al. [10] have reported that factors associated with falls include age, past medical history (stroke, orthostatic hypotension, and dizziness), cognitive function, depression, and medications.

Many studies have attempted to identify various risk factors associated with elderly falls. However, most of these studies were conducted using interviews and surveys $[1,3,9,10]$. Descriptive studies analyzing endogenous factors such as lower limb strength, torque, and sarcopenia increasing the risk of falls in the elderly are lacking. Few studies have measured the lower limb strength, torque, and skeletal muscle mass in the rural elderly population.

Loss of muscle strength due to increasing age has been suggested as one of the main factors contributing to functional limitation or gait abnormality in the activities of daily living $[6,9,11,12]$. Sohng and Choi [9] have reported a higher risk of falls in subjects with weakened ankle muscle strength, which decreases coping ability leading to loss of balance and results in falls. Hortobagyi et al. [11] have shown that elderly people exhibit muscle weakness due to musculoskeletal degenerative changes and underlying diseases. Therefore, falls can be triggered by a change in walking and a decrease in balance control function. 'Torque', the rotational effect involving muscles and joints, contributes to decreased muscle strength and walking ability [6]. Measurement of strength and torque is important when measuring the risk of falls in the elderly. Other studies reported that the knee or ankle strength determine the risk of falling in the elderly $[4,9]$. Compared with previous studies, we found that hip strength, hip torque, knee torque, and knee strength were risk factors.

We evaluated the risk factors for falls in the rural elderly and analyzed the characteristics. Because of the differences in living environment between rural and urban areas, it is necessary to analyze the fall factors in rural areas. In this study, we conducted a questionnaire survey of the demographic characteristics, social environment, cognitive function, and educational level of subjects. Compared with previous studies, we performed a physical examination using objective measurement tools to determine whether sarcopenia, knee osteoarthritis, leg muscle strength, hip, and knee torque were associated with the risk factors of falls in the elderly residents of ru- 
ral areas. We analyzed the causes of falls and risk factors in the elderly population in rural areas and identified differences between fall and non-falls groups. This study provides basic data underlying the causes of falls among the rural elderly Koreans.

\section{MATERIALS AND METHODS}

This retrospective study included elderly farmers living in rural areas registered with Gyeongsang National University Hospital's Center for Farmer's Safety and Health between March 2016 and December 2016. We contacted registered farmers by phone or mail to visit the hospital once for questionnaire survey and undergo physical examination. When participants visited the hospital, they were asked about demographic characteristics, social environment, and educational level using a questionnaire. The physical examination was performed in the following order: cognitive function, lower leg strength and torque, body composition, and knee image test. This study was approved by the Institutional Review Board of Gyeongsang National University Hospital (No. 2016-04-001).

\section{Participants}

In this study, a fall was defined as "falling over to a lower position or floor, except falls due to external forces, loss of consciousness or paralysis, regardless of the person's intention" [1]. A person who fell to the floor at least once in the past year was defined as a faller. Subjects aged more than 65 years were considered elderly.

A sample of 350 elderly subjects were recruited from the farmers' health promotion project. They were divided into two groups: 254 non-fallers and 96 fallers. The subjects were excluded from the study if they met one or more of the following exclusion criteria: central nervous system diseases including stroke, Parkinson disease, Alzheimer disease; behavioral or mental disorder limiting the comprehension of simple test-related instructions (e.g., rising from the chair, walking, turning around, sitting down, standing still, etc.); and blindness.

\section{Demographic characteristics}

Demographic characteristics were assessed by interview using a questionnaire. The questionnaire consisted of sex, age, weight $(\mathrm{kg})$, height $(\mathrm{cm})$, relationship with family or relatives, final academic background, smoking history, alcohol consumption, and the number of falls in the previous year.

\section{Cognitive function test}

Cognitive function was assessed using the modified version of the Mini-Mental State Exam (MMSE) due to low levels of schooling in the elderly population living in rural areas. This test comprised 13 items independent of schooling with a total possible score ranging from 0 to 20 points. A higher score pointed toward normal health status while lower scores suggested possible dementia [13].

\section{Lower extremity strength and power}

The maximal isokinetic strength and torque of lower extremity were measured with a Biodex System 4 isokinetic dynamometer (Biodex Medical System, Shirley, NY, USA). To measure the hip joint, subjects were asked to lay down on a hard bed and asked to move the body to the maximum exercise position. The participant's waist was fixed and the strap was placed on the proximal thigh to extend from flexion to extension at $45^{\circ}$ and $300^{\circ}$ per second. The knee was slightly flexed during extension. To measure the knee joint, the subject was seated in a hard chair. The distal thigh was fixed and straps were placed on the ankle to perform the movement from maximum flexion to extension at $60^{\circ}$ and $180^{\circ}$ per second. The ankle was maintained neutral while moving from knee flexion to extension. The test was repeated twice with a rest period of 30 seconds between tests, and the knee test was conducted after hip test. Verbal encouragement was provided to the subjects for accurate examination during testing. Older participants showed reduced muscle function across the entire range as well as in just one position. The results of measurement varied due to limited cooperation of each subject. Therefore, the measured values of the muscle force and the torque at the angular velocity were averaged to reduce the variation.

\section{Body composition}

Body composition of all the participants was measured using whole body dual X-ray absorptiometry. Bone mineral density (BMD), fat mass, and lean soft-tissue mass of the body including arms and legs were measured separately. Lean soft-tissue masses of the arms and legs were nearly equal to skeletal muscle mass. Due to correlation between absolute muscle mass and height, the skeletal 
muscle mass index (SMI) was calculated using the following formula:

$$
\mathrm{SMI}=\frac{\text { Lean mass }(\mathrm{kg})}{\text { Height }\left(\mathrm{m}^{2}\right)}
$$

Appendicular SMI was defined as the sum of arm and leg SMIs. Sarcopenia was defined according to the Asia Working Group for Sarcopenia criteria (SMI, $<5.4 \mathrm{~kg} / \mathrm{m}^{2}$ for women and $<7.0 \mathrm{~kg} / \mathrm{m}^{2}$ for men) [14].

Absolute BMD $\left(\mathrm{g} / \mathrm{cm}^{2}\right)$ values of lumbar spine, total femur, and femoral neck were measured using dual energy $\mathrm{X}$-ray absorptiometry. According to WHO criteria, osteoporosis was defined by a BMD T-score less than -2.5 .

\section{Knee osteoarthritis}

Radiological examinations were performed to confirm knee arthritis. Osteoarthritis was defined by KellgrenLawrence grade of 2 or more [15].

\section{Statistical analysis}

All statistical analyses were performed using SPSS version 20.0 (IBM, Armonk, NY, USA). The characteristics of fallers and non-fallers were compared via crosstabulation of nominal variables. An independent sample t-test was used when the variable was continuous. The level of statistical significance was set at $\mathrm{p}<0.05$. In case of crossover analysis, the p-value of Fisher accuracy test was used when the expected frequency of the cells was 5 or less. Logistic regression analysis was performed to identify the risk factors for fall when the p-value of the variable was 0.05 or less. Falling experience, the dependent variable (outcome variable), had a binary value ( 0 and 1 ). A logistic regression model was used to test the effect of independent variables while univariate and multivariate analyses were performed by fitting significant variables in descriptive statistics to the model. Odds ratios (ORs) and corresponding 95\% confidence intervals (CIs) were calculated for logistic regression. After performing univariate analysis and confirming multicollinearity of factors related to falls, multivariate analysis was performed to confirm factors with poor correlation.

\section{RESULTS}

Participants' demographic characteristics

A total of 350 people participated in this study including
93 males and 257 females. The 93 males included 80 (86\%) in the non-faller group and $13(14 \%)$ in the faller group. The 257 women included $174(67.7 \%)$ in the non-faller group and $83(32.3 \%)$ in the faller group. The average age of all participants was 69 years. Significant differences were found in gender $(\mathrm{p}=0.001)$, age $(\mathrm{p}=0.003)$, living arrangement $(\mathrm{p}<0.001)$, and final academic background $(p<0.001)$ between the faller and the non-faller groups. However, a history of cigarette smoking $(\mathrm{p}=0.184)$ and alcohol drinking ( $\mathrm{p}=0.262$ ) was not significantly different between the two groups (Table 1).

\section{Comparison of factors based on fall history}

Skeletal muscle mass $(\mathrm{p}=0.004)$, MMSE $(\mathrm{p}=0.01)$, mean

Table 1. Demographic characteristics based on the history of falls

\begin{tabular}{|c|c|c|c|}
\hline Characteristic & $\begin{array}{c}\text { Non-faller } \\
(\mathrm{n}=\mathbf{2 5 4})\end{array}$ & $\begin{array}{c}\text { Faller } \\
(n=96)\end{array}$ & p-value \\
\hline Gender & & & $0.001^{* *}$ \\
\hline Male & $80(86.0)$ & $13(14.0)$ & \\
\hline Female & $174(67.7)$ & $83(32.3)$ & \\
\hline Age (yr) & & & $0.003^{* *}$ \\
\hline$<60$ & $41(87.2)$ & $6(12.8)$ & \\
\hline $60-69$ & $98(78.4)$ & $27(21.6)$ & \\
\hline $70-79$ & $91(62.8)$ & $54(37.2)$ & \\
\hline$\geq 80$ & $24(72.7)$ & $9(27.3)$ & \\
\hline Smoking & & & 0.184 \\
\hline Smoker & $21(84.0)$ & $4(16.0)$ & \\
\hline Non smoker & $233(71.7)$ & $92(28.3)$ & \\
\hline $\begin{array}{l}\text { Past year alcohol } \\
\text { drinker }\end{array}$ & & & 0.262 \\
\hline Alcohol drinker & $244(73.3)$ & $89(26.7)$ & \\
\hline Non-alcohol drinker & $10(58.8)$ & $7(41.2)$ & \\
\hline Living arrangement & & & $<0.001^{* * *}$ \\
\hline $\begin{array}{l}\text { Lives with family } \\
\text { or relatives }\end{array}$ & $171(79.5)$ & $44(20.5)$ & \\
\hline Lives alone & $83(84.6)$ & $52(15.5)$ & \\
\hline $\begin{array}{l}\text { Final academic } \\
\text { background }\end{array}$ & & & $0.001^{* *}$ \\
\hline $\begin{array}{l}\text { Less than middle } \\
\text { school graduate }\end{array}$ & $161(67.1)$ & $79(32.9)$ & \\
\hline $\begin{array}{l}\text { More than middle } \\
\text { school graduate }\end{array}$ & $93(84.6)$ & $17(15.5)$ & \\
\hline
\end{tabular}

Values are presented as number of patients (\%). ${ }^{* *} \mathrm{p}<0.01,{ }^{* * *} \mathrm{p}<0.001$. 
hip torque $(\mathrm{p}=0.004)$, mean hip power $(\mathrm{p}=0.001)$, mean knee torque $(p<0.001)$, mean knee power $(p<0.001)$, and knee osteoarthritis $(\mathrm{p}=0.003)$ varied significantly between faller and non-faller groups. However, osteoporosis $(\mathrm{p}=0.1309)$ and sarcopenia $(\mathrm{p}=0.7714)$ were not significantly different between the groups (Table 2 ).

\section{Univariate logistic analysis of variables for falls}

Univariate logistic analysis was performed based on statistically significant demographic features and comparative factors including gender, age, living arrangement, final academic background, skeletal muscle mass, MMSE, knee osteoarthritis, and mean values of hip torque, hip power, knee torque, and knee power. In fallers, female gender $(p=0.001)$, age ( $70-79$ years, $p=0.003)$, living alone $(p<0.001)$, education less than middle school $(p=0.001)$, skeletal muscle mass $(p=0.004)$, MMSE $(p=0.005)$, knee osteoarthritis $(\mathrm{p}=0.003)$, mean hip torque $(\mathrm{p}=0.005)$, mean hip power $(\mathrm{p}=0.005)$, mean knee torque $(\mathrm{p}<0.001)$, and mean knee power $(\mathrm{p}<0.001)$ were significant factors related to falls (Table 3 ).

Table 2. Comparison of factors based on fall history

\begin{tabular}{|c|c|c|c|}
\hline Characteristic & $\begin{array}{c}\text { Non-faller } \\
(\mathrm{n}=254)\end{array}$ & $\begin{array}{c}\text { Faller } \\
(\mathrm{n}=96)\end{array}$ & p-value \\
\hline Skeletal muscle mass & $22.62 \pm 4.71$ & $21.01 \pm 4.13$ & $0.004^{* *}$ \\
\hline MMSE & $18.89 \pm 1.57$ & $18.29 \pm 2.05$ & $0.01^{*}$ \\
\hline Hip torque mean & $56.2 \pm 22.4$ & $45.9 \pm 20.9$ & $0.004^{* *}$ \\
\hline Hip power mean & $33.8 \pm 20.0$ & $24.8 \pm 15.6$ & $0.001^{* *}$ \\
\hline Knee torque mean & $45.4 \pm 18.0$ & $36.4 \pm 15.9$ & $<0.001^{* * *}$ \\
\hline Knee power mean & $39.2 \pm 17.8$ & $30.3 \pm 16.5$ & $<0.001^{* * *}$ \\
\hline Osteoporosis & & & 0.1309 \\
\hline Normal & $91(79.8)$ & $23(20.2)$ & \\
\hline Osteopenia & $111(68.9)$ & $50(31.1)$ & \\
\hline Osteoporosis & $47(72.3)$ & $18(27.7)$ & \\
\hline Knee osteoarthritis & & & $0.003^{* *}$ \\
\hline Normal & $203(76.6)$ & $62(23.4)$ & \\
\hline Knee osteoarthritis & $51(60.0)$ & $34(40.0)$ & \\
\hline Sarcopenia & & & 0.7714 \\
\hline Normal & $220(72.9)$ & $82(27.2)$ & \\
\hline Sarcopenia & $34(70.8)$ & $14(29.2)$ & \\
\hline
\end{tabular}

Values are presented as mean \pm standard deviation or number (\%).

MMSE, Mini-Mental State Exam.

${ }^{*} \mathrm{p}<0.05,{ }^{* *} \mathrm{p}<0.01,{ }^{* * *} \mathrm{p}<0.001$.

\section{Multivariate logistic analysis of variables for falls}

Multivariate logistic analysis was performed to identify variables most relevant to falls among statistically significant factors in univariate regression analysis. As a result of the analysis, it was confirmed that gender and age were statistically significant factors. In the faller group, female gender (OR=8.36; 95\% CI, 1.64-42.53; $\mathrm{p}=0.011)$ increased the risk of falling 8.36-fold compared with male gender. The age range of $70-79$ years $(\mathrm{OR}=4.72 ; 95 \%$ CI, 1.01-22.16; $\mathrm{p}=0.049$ ) was associated with a 4.72 -fold higher risk of falling compared with age below 60 years (Table 3).

\section{DISCUSSION}

We identified the causes and risks of falls in the elderly living in rural areas of Korea. Falls are major health events in the elderly causing functional impairment and affecting their quality of life. In a previous study, $13.3 \%$ of the elderly reported functional limitations after a fall [16]. A study by Tripathy et al. [17] also reported that $14 \%$ of participants experienced limited mobility and self-management problems after a fall. Unlike urban areas, elderly people living in rural areas exhibit different characteristics according to their living environment, and regional and demographic characteristics. Most elderly people in rural areas live alone, fail to exercise, manifest chronic diseases, and have low educational level $[5,8]$. Therefore, it is necessary to identify the factors that increase the risk of falls in the rural elderly residents.

We first identified the risk factors for falls based on the gender of the rural elderly participants, and found that females were 4.2 -fold more likely to fall than males. This finding may be attributed to lower bone formation in females than in males, and increased bone resorption due to decreased estrogen levels [18]. Higher age and female gender have been reported to be significantly associated with falls in a previous study [16]. Lim et al. [1] have reported that females exhibit a higher falling rate with worse post-fall results than males. Tromp et al. [19] have shown that despite insignificant differences in the incidence of repetitive falls between females and males a higher number of females sustained a single fall compared with males. In our study, females showed a statistically significant higher risk for falls than males in both univariate and multivariate analyses. The higher risk of 
Table 3. Univariate and multivariate analyses based on fall history

\begin{tabular}{|c|c|c|c|c|}
\hline \multirow{2}{*}{ Variable } & \multicolumn{2}{|c|}{ Univariate } & \multicolumn{2}{|c|}{ Multivariate } \\
\hline & OR (95\% CI) & p-value & OR (95\% CI) & p-value \\
\hline \multicolumn{5}{|l|}{ Gender } \\
\hline Male & 1 (Ref) & & 1 (Ref) & \\
\hline Female & $2.94(1.55-5.58)$ & $0.001^{* *}$ & $8.36(1.64-42.53)$ & $0.011^{*}$ \\
\hline \multicolumn{5}{|l|}{ Age (yr) } \\
\hline$<60$ & 1 (Ref) & & 1 (Ref) & \\
\hline $60-69$ & $1.88(0.72-4.90)$ & 0.195 & $1.78(0.48-6.58)$ & 0.387 \\
\hline $70-79$ & $4.06(1.62-10.18)$ & $0.003^{* *}$ & $4.72(1.01-22.19)$ & $0.049 *$ \\
\hline$\geq 80$ & $2.56(0.81-8.09)$ & 0.109 & $1.70(0.18-15.85)$ & 0.64 \\
\hline \multicolumn{5}{|l|}{ Living arrangement } \\
\hline Lives with family or relatives & 1 (Ref) & & 1 (Ref) & \\
\hline Lives alone & $2.44(1.51-3.93)$ & $<0.001^{* * *}$ & $1.72(0.79-3.76)$ & 0.174 \\
\hline \multicolumn{5}{|l|}{ Final academic background } \\
\hline More than middle school graduate & 1 (Ref) & & 1 (Ref) & \\
\hline Less than middle school graduate & $2.68(1.50-4.81)$ & $0.001^{* *}$ & $1.19(0.40-3.56)$ & 0.76 \\
\hline MMSE & $0.83(0.73-0.95)$ & $0.005^{* *}$ & $0.81(0.64-1.03)$ & 0.08 \\
\hline Knee osteoarthritis & $2.18(1.30-3.67)$ & $0.003^{* *}$ & $1.69(0.73-3.89)$ & 0.22 \\
\hline Skeletal muscle mass & $0.92(0.87-0.97)$ & $0.004^{* *}$ & $1.07(0.93-1.23)$ & 0.329 \\
\hline Hip torque mean & $0.98(0.96-0.99)$ & $0.005^{* *}$ & $1.01(0.94-1.07)$ & 0.879 \\
\hline Hip power mean & $0.97(0.95-0.99)$ & $0.005^{* *}$ & $0.97(0.91-1.04)$ & 0.436 \\
\hline Knee torque mean & $0.97(0.95-0.98)$ & $<0.001^{* * *}$ & $0.99(0.90-1.09)$ & 0.797 \\
\hline Knee power mean & $0.97(0.95-0.98)$ & $<0.001^{* * *}$ & $1.05(0.96-1.16)$ & 0.292 \\
\hline
\end{tabular}

Adjusted for gender, age, living arrangement, education, skeletal muscle mass, MMSE, knee osteoarthritis, mean values of hip torque, hip power, knee torque, and knee power.

OR, odds ratio; CI, confidence interval; MMSE, Mini-Mental State Exam.

${ }^{*} \mathrm{p}<0.05,{ }^{* *} \mathrm{p}<0.01,{ }^{* * *} \mathrm{p}<0.001$.

falls in females is generally related to physical and hormonal characteristics associated with aging. However, demographic characteristics of rural areas were also investigated in this study. The results suggested a difference in sex ratios depending on the region related to population movements and longevity $[7,8]$.

In a previous study, the average age of faller was 78.1 years and that of non-faller was 69.8 years [20]. The fall rate increased with age, with $50 \%$ of people over the age of 80 sustaining falls each year. The fall rate was the highest $(42.6 \%)$ in patients above 75 years of age, $38.3 \%$ in patients between 65 and 75 years of age, and $19.1 \%$ in those between 60 and 64 years of age [5]. This result was attributed to age-related deterioration and functional failure. In this study, the rate of falls was the highest $(37.2 \%)$ in the age group of $70 \mathrm{~s}$, and the lowest $(12.4 \%)$ in those in their 60s. It was $27.3 \%$ in the age group of 80 s. Univariate and multivariate analyses showed a statistically significant risk of falls in the elderly population aged between 70 and 79 years. In rural areas, aging is on the rise usually among those in the 70s. A high proportion of people in this age group is engaged in agriculture. Conversely, productivity was reduced among those above the age of 80 years [8]. Differences in agricultural activities and age distribution are associated with the risk of falling. The elderly included in this study were highly distributed in the age group of 70-79 years. Therefore, aging may be an important risk factor for falls in rural elderly, especially those in the age category of 70-79 years.

Avlund et al. [21] have reported that falls were associated with decreased muscle strength and equilibrium suggesting that improvement in strength and balance might be an important factor in fall prevention. Previous studies have shown that decreased muscle strength, weakened 
leg muscles due to decreased muscle mass, and progressively decreased coordination of ankle and knee after age 60 increase the risk of falls [22]. Other studies reported that the elderly residing in the rural areas have lower strength than those living in the community and those who sustained falls showed lower leg strength and slower walking pace compared with those without falls [20,23]. Leg extension strength is required for balance recovery after tripping, which explains why the measurement of joint extension in lower limbs is the best approach to identify fallers [24]. In several studies, knee strength and torque changes were measured $[23,24]$. Patients with hip joint abnormality also manifest muscle weakness, gait disturbance, and balance deficits that potentially increase the risk of falls [25]. Therefore, it was necessary to identify risk factors for falls depending on the changes in the force of hip joint muscles. Thus, we measured additional hip torque and muscle strength. Measurement of isokinetic strength has been suggested as the simplest method to accurately measure the force-producing capabilities of muscles [26]. The force created by muscles generates a 'torque' around the joint calculated as the vertical distance between the line of force produced by muscles and the center of the joint movement [6]. An increase in torque increases the muscle strength while a reduction in torque limits the muscle strength. Our study was the first report to measure the risk of falls in elderly people by measuring the strength and torque of the hip and knee together. We hypothesized that the reduction in hip and knee strength and torque values increased the risk of falls. However, multivariate analysis did not reveal any significant association between strength and torque values of hip and knee, contrary to our hypothesis, probably due to the following reasons. First, elderly people living in rural areas engaged in agriculture for a long time and most of them complained of chronic pain. Second, they included many cases of back, knee, and leg surgeries for musculoskeletal diseases. Therefore, it was difficult to maintain the correct posture during examination. Thus, our results may be affected by participants' inability to exercise to obtain adequate muscle strength and torque.

As age increases, muscle mass decreases due to decreased bone density. Therefore, the rate of falls experienced is very high in the age group of 80 years or older [20]. The likelihood of functional impairment and disability was approximately twice that of older men and three times greater in older women with sarcopenia than in older men and women with non-sarcopenia. Aging and low frequency of physical activity decreases the muscle strength by approximately $0.75 \%-1.0 \%$ each year since the age of 30 [27]. We hypothesized that the elderly living in rural areas lose muscle mass due to chronic illness and the lack of exercise may increase the risk of falls. However, in our study, sarcopenia was not found to be a significant risk factor for falls. It was concluded that the number of subjects included in the study was too small to analyze the factors inducing sarcopenia, which might have affected the outcome.

Choi et al. [28] reported that the elderly subjects living with families experience fewer falls than those living alone. In our study, the results of univariate analysis showed a higher likelihood of falls if they lived alone than when they lived with their family. However, multivariate analysis did not show significant differences in falls sustained. One study found that elderly individuals who were living alone had significantly lower cognitive function because they were more likely to have isolated life due to lack of stimulation or sensation, and high boredom [9]. However, the elderly living in rural areas often work with the people around them doing farming or other tasks. In addition, most of their activities are repetitive and maintain communication with neighbors. These characteristics differ from the elderly living in urban areas.

Mechanical receptors near the knee joint may be vulnerable to anatomical changes caused by osteoarthritis, thus increasing the risk of patient falls due to knee osteoarthritis [29]. Osteoarthritis damages the joint sensation, disturbs knee movement, and reduces muscle strength, thus increasing the risk of falls due to the loss of dynamic posture control [30,31]. Patients with severe knee osteoarthritis often suffer from weakened muscle strength limited quality of life, and increased risk of falls [32]. In this study, univariate analysis showed that knee osteoarthritis was associated with falls. However, multivariate analysis did not show any statistically significant association between knee osteoarthritis and risk for falls. We expected that older people living in rural areas show an increased osteoarthritis of the knee because of repetitive farming and traditional lifestyles. However, few of the elderly included in our study complained of knee osteoarthritis because the subjects included were limited to residents 
living in a specific area, in contrast to those living in all rural areas.

Falls can be caused by various risk factors. Osteoporosis is a disease in which bone strength is lowered by the increased risk of fracture. In general, women have lower bone mass than men and estrogen levels that prevent osteoporosis are sharply decreased after menopause, which increases the risk of osteoporosis [33]. Decreased BMD and fractures caused by falls reduces the quality of life in the elderly [5]. However, our study showed that osteoporosis was not a significant risk factor for falls probably because there were fewer patients with osteoporosis among the total participants and the lowest number of patients in the faller group compared to the non-faller group.

A significant difference existed in the ratio of uneducated individuals sustaining falls and those who never had falls ( $60.2 \%$ vs. $35.5 \%$, respectively) [20]. Also, those who graduated only elementary school showed a 3.15 -fold higher risk of falling than those who graduated from middle school or higher [28]. Based on information obtained from our study, we found that more than half of the participants in the study area failed to graduate from middle school. Therefore, educational levels were determined by whether or not the subjects attended middle school. Univariate analysis showed that the risk of falls was twice as high among those who were educated less than middle school. However, this education factor was not statistically significant in multivariate analysis. Although there were a large number of participants who were educated less than middle school in the faller group, the level of education alone may not limit the risk of falls. Other factors should be considered together.

Cognitive impairment of the elderly refers to impaired cognitive function and disorientation, or impaired judgment [34]. Dementia is rapidly increasing in elderly people aged 65 years and older. Senile dementia induces a wide range of cognitive dysfunction that increases the risk of falls [35]. Similar results were obtained in this study. In univariate analysis, MMSE was found to be a significant risk factor for falls. It was found that the higher the MMSE score, the lower was the risk of falls. However, in multivariate analysis, MMSE was not a statistically significant factor for falls. Most of the elderly residents of rural areas did not have high academic levels. Experience and skills are more important than agronomic knowledge for elderly farmers. There was a slight difference in scores of cognitive function between fall and non-fall groups included in our study. However, their academic level was similar. Therefore, it is difficult to judge whether the risk factor for falls can be increased by only cognitive function score. Elderly people in rural areas require skills, experience, tips, and recognized environmental changes.

This study has some limitations. First, the number of male participants was less than that of females and the number of fallers was smaller suggesting that recruitment of subjects in a specific region reflected the distribution of population. We selected specific rural areas with a large number of elderly people. Thus, it was difficult to control gender and participant differences in the region. Second, we could not determine personal characteristics of subjects depending on disease. Dizziness, postural hypotension, impaired mobility, use of analgesics and antiepileptic drugs are proven predictors most strongly associated with recurrent falls in the elderly [17]. However, the underlying diseases of subjects and medications used were unknown. We could not identify the risk of falls due to differences in such factors. Third, when measuring leg strength and torque, we could not distinguish the limited factors of measurement. Results of this study might be inaccurate if the same method was used without considering functional limitations due to musculoskeletal pain and disease.

The purpose of this study was to investigate the risk factors for fall and provide useful data for the prevention of falls by analyzing the risk factors in the elderly in rural areas. Based on results of the present study, the following factors need to be considered in the future to identify fall risk and establish effective prevention measures. First, it is necessary to develop evaluation tools that can measure the physical function in the elderly residents in the rural areas. Most leg strength can be confirmed using manual muscle test. However, it lacks objective information. Our study attempted to measure muscle strength and torque objectively. Unfortunately, it was difficult to measure because the machine was large and heavy. Second, the risk factors for falls in rural areas vary because of the different regional characteristics, population distribution, and living environment. Therefore, it is necessary to analyze several areas to obtain further information related to falls.

Results of this study can be used to evaluate fall preventive factors in a comprehensive manner. They can be 
also used as basic data to determine the risk factors for falls in rural areas. In addition, since environmental and regional factors vary in each community, it is necessary to evaluate other regions in the future. Based on these results, we conclude that female gender and elderly status (70-79 years) are important risk factors for falls in rural areas. Therefore, special consideration should be focused on these factors in evaluating the risk in the rural elderly population.

\section{CONFLICT OF INTEREST}

No potential conflict of interest relevant to this article was reported.

\section{AUTHOR CONTRIBUTION}

Conceptualization: Lee CH, Jo H, Park D. Methodology: Lee CH, Park D. Formal analysis: Park D, Yoon CH, Oh MK. Funding acquisition: Lee $\mathrm{CH}$, Oh MK. Project administration: Lee CH, Lee ES. Visualization: Lee ES, Yoon $\mathrm{CH}$. Writing - original draft: Park D, Jo H, Lee CH. Writing - review and editing: Park D, Lee CH. Approval of final manuscript: all authors.

\section{REFERENCES}

1. Lim JY, Park WB, Oh MK, Kang EK, Paik NJ. Falls in a proportional region population in Korean elderly: incidence, consequences, and risk factors. J Korean Geriatr Soc 2010;14:8-17.

2. Leveille SG, Bean J, Bandeen-Roche K, Jones R, Hochberg M, Guralnik JM. Musculoskeletal pain and risk for falls in older disabled women living in the community. J Am Geriatr Soc 2002;50:671-8.

3. Cho JP, Paek KW, Song HJ, Jung YS, Moon HW. Prevalence and associated factors of falls in the elderly community. Korean J Prev Med 2001;34:47-54.

4. de Rekeneire N, Visser M, Peila R, Nevitt MC, Cauley JA, Tylavsky FA, Simonsick EM, Harris TB. Is a fall just a fall: correlates of falling in healthy older persons. The Health, Aging and Body Composition Study. J Am Geriatr Soc 2003;51:841-6.

5. Kim JY, Lee YW, Ham OK. Factors related to fall in elderly patients with osteoporosis. Korean J Adult Nurs 2009;21:257-67.
6. Kiel DP, O'Sullivan P, Teno JM, Mor V. Health care utilization and functional status in the aged following a fall. Med Care 1991;29:221-8.

7. Jang SN, Cho SI, Oh SW, Lee ES, Baik HW. Time since falling and fear of falling among community-dwelling elderly. Int Psychogeriatr 2007;19:1072-83.

8. Song KC, Kim DK. Activities of daily living of elderly in a rural area and study for related factors. J Korean Geriatr Soc 2002;6:29-40.

9. Sohng KY, Choi DW. Instrumental activities of daily living, leg muscle strength, cognitive and visual function according to demographic variables and the experience of falling in community resident elderly Koreans. J Korean Acad Fundam Nurs 2007;14:221-9.

10. Ryeom TH, Kim SY, So YK, Park SY, Lee JH, Cho HS, et al. The risk factors of falls in the elderly. J Korean Acad Fam Med 2001;22:221-9.

11. Hortobagyi T, Mizelle C, Beam S, DeVita P. Old adults perform activities of daily living near their maximal capabilities. J Gerontol A Biol Sci Med Sci 2003;58:M453-60.

12. Sapega AA. Muscle performance evaluation in orthopaedic practice. J Bone Joint Surg Am 1990;72:156274.

13. Folstein MF, Folstein SE, McHugh PR. "Mini-mental state". A practical method for grading the cognitive state of patients for the clinician. J Psychiatr Res 1975;12:189-98.

14. Chen LK, Liu LK, Woo J, Assantachai P, Auyeung TW, Bahyah KS, et al. Sarcopenia in Asia: consensus report of the Asian Working Group for Sarcopenia. J Am Med Dir Assoc 2014;15:95-101.

15. Petersson IF, Boegard T, Saxne T, Silman AJ, Svensson B. Radiographic osteoarthritis of the knee classified by the Ahlback and Kellgren \& Lawrence systems for the tibiofemoral joint in people aged 35-54 years with chronic knee pain. Ann Rheum Dis 1997;56:493-6.

16. Sirohi A, Kaur R, Goswami AK, Mani K, Nongkynrih B, Gupta SK. A study of falls among elderly persons in a rural area of Haryana. Indian J Public Health 2017; 61:99-104.

17. Tripathy NK, Jagnoor J, Patro BK, Dhillon MS, Kumar R. Epidemiology of falls among older adults: a cross sectional study from Chandigarh, India. Injury 2015;46:1801-5.

18. Seeman E. Pathogenesis of bone fragility in women 
and men. Lancet 2002;359:1841-50.

19. Tromp AM, Pluijm SM, Smit JH, Deeg DJ, Bouter LM, Lips P. Fall-risk screening test: a prospective study on predictors for falls in community-dwelling elderly. J Clin Epidemiol 2001;54:837-44.

20. Sing MS, Kim SK, Kim NC. Comparison of body composition, physical fitness and experience of falls in elders in the rural community. J Korean Gerontol Nurs 2009;11:195-203.

21. Avlund K, Schroll M, Davidsen M, Lovborg B, Rantanen T. Maximal isometric muscle strength and functional ability in daily activities among 75-year-old men and women. Scand J Med Sci Sports 1994;4:3240.

22. Tinetti ME, Baker DI, McAvay G, Claus EB, Garrett P, Gottschalk M, et al. A multifactorial intervention to reduce the risk of falling among elderly people living in the community. N Engl J Med 1994;331:821-7.

23. Sieri T, Beretta G. Fall risk assessment in very old males and females living in nursing homes. Disabil Rehabil 2004;26:718-23.

24. Pijnappels M, van der Burg PJ, Reeves ND, van Dieen $\mathrm{JH}$. Identification of elderly fallers by muscle strength measures. Eur J Appl Physiol 2008;102:585-92.

25. Ikutomo H, Nagai K, Tagomori K, Miura N, Nakagawa $\mathrm{N}$, Masuhara K. Incidence and risk factors for falls in women with end-stage hip osteoarthritis. J Geriatr Phys Ther 2018 Jan 18 [Epub]. http://doi.org/10.1519/ JPT.0000000000000156.

26. Scudder GN. Torque curves produced at the knee during isometric and isokinetic exercise. Arch Phys Med Rehabil 1980;61:68-73.
27. Janssen I, Heymsfield SB, Ross R. Low relative skeletal muscle mass (sarcopenia) in older persons is associated with functional impairment and physical disability. J Am Geriatr Soc 2002;50:889-96.

28. Choi KW, Park UA, Lee IS. Factors influencing the fear of falling according to gender in frail elderly. J Korean Gerontol Soc 2011;31:539-51.

29. Wu YT, Hsu KC, Li TY, Chang CK, Chen LC. Effects of platelet-rich plasma on pain and muscle strength in patients with knee osteoarthritis. Am J Phys Med Rehabil 2018;97:248-54.

30. Kirkley A, Webster-Bogaert S, Litchfield R, Amendola A, MacDonald S, McCalden R, et al. The effect of bracing on varus gonarthrosis. J Bone Joint Surg Am 1999; 81:539-48.

31. Mat S, Ng CT, Tan MP. Influence of hip and knee osteoarthritis on dynamic postural control parameters among older faller. J Rehabil Med 2017;49(3):258-63.

32. Ettinger WH Jr, Burns R, Messier SP, Applegate W, Rejeski WJ, Morgan T, et al. A randomized trial comparing aerobic exercise and resistance exercise with a health education program in older adults with knee osteoarthritis. The Fitness Arthritis and Seniors Trial (FAST). JAMA 1997;277:25-31.

33. Son SM, Chun YN. Association of bone densities with anthropometric indices and lifestyles in elderly people. Korean J Community Nutr 2002;7:327-35.

34. Yoon J. Adult, elderly psychology. Seoul, Korea: Chung-Ang Aptitude Publishing; 1999.

35. Rhee JA, Jung HG. A study on the depression and cognitive impairment in the rural elderly. Korean J Prev Med 1993;26:412-29. 